\title{
Using Water Stress to Control Vegetative Growth and Productivity of Temperate Fruit Trees
}

\author{
R. Scott Johnson ${ }^{1}$ and Dale F. Handley \\ Department of Pomology, University of California, Kearney Agricultural Center, 9240 S. Riverbend Avenue, \\ Parlier, CA 93648
}

Water stress almost always reduces yield in agricultural crops. Numerous studies have demonstrated the negative impact of water stress on various plant processes (Bradford and Hsiao, 1982). A close correlation exists between water use or evapotranspiration and final yield in annual crops (Hanks, 1983), so stress should be avoided at all stages of development. However, for mature fruit trees, this relationship may not hold in many situations, thus providing the opportunity for saving water without reducing production.

The perennial nature of fruit trees helps provide this opportunity. Because a mature tree already has grown a supporting structure of scaffolds and branches, it can rapidly grow a full canopy of leaves in the spring to maximize light interception and provide renewal fruiting wood for the following year. Further vegetative growth does not substantially increase total light interception and is generally undesirable growth that must be pruned out later. Therefore, imposing moderate water stress to reduce vegetative growth may have no negative effect on total photosynthate production and continued productivity. In fact, even beneficial results may be obtained because of less shading of lower and interior fruiting wood, better light distribution throughout the tree, and reduced need for summer and dormant pruning.

Reduced canopy development (shoot growth and leaf expansion) is one of the earliest responses to water stress, occurring before stomatal closure and reduction of photosynthesis (Bradford and Hsiao, 1982). Theoretically, this should allow for greater availability of carbohydrates for the growth of other organs. Indeed, increased root growth has been demonstrated under moderate water stress (Sharp and Davies, 1975). In fruit trees the goal is to divert these carbohydrates into fruit growth. Since fruit growth tends to dominate over vegetative growth (Higgs and Jones, 1991; Lenz, 1967), we have hypothesized that moderate water stress will not reduce fruit growth and may even promote it (Fig. 1). The idea of purposely imposing moderate stress to achieve certain beneficial results has generally been termed regulated deficit irrigation (RDI) (Behboudian and Mills, 1997). Of course, moderate, beneficial stress can quickly turn into severe, harmful stress (point A in Fig. 1) and may depend on many factors, such as variety, environmental conditions, and timing of the stress. This emphasizes the need to accurately measure stress and to thoroughly understand the processes occurring in the tree as moderate stress develops.

Timing of RDI is critical, especially in temperate fruit trees in which growth of the various organs tends to occur at different times of the season (Chalmers et al., 1985). We have hypothesized that temperate fruit trees can tolerate or benefit from moderate water stress during two periods. First, the period after harvest should have potential because no fruit is present and the concern is with proper development of fruit buds for next year's crop. With early maturing varieties, this period can be quite long, so the potential for water savings is substantial. The second period is during the lag phase (stage II) of peach [Prunus persica (L.) Batsch] fruit growth (Lilleland, 1933). Stone fruit typically follow a double sigmoid pattern of growth. Rapid periods of growth after bloom and before harvest are separated by a slower lag phase of growth. Since fruit diameter is increasing more slowly, water stress should have only a minor effect on fruit growth but a major impact on vegetative growth. During the subsequent period of rapid

Received for publication 15 Sept. 1999. Accepted for publication 18 Oct. 1999. The cost of publishing this paper was defrayed in part by the payment of page charges. Under postal regulations, this paper therefore must be hereby marked advertisement solely to indicate this fact.

${ }^{1}$ Corresponding author. Email address: sjohnson@uckac.edu fruit growth (stage III) carbohydrates should be diverted from vegetative growth into fruit growth.

\section{POSTHARVEST WATER STRESS}

Larson et al. (1988), working with a June-harvested peach cultivar in California reported no loss of production or fruit size when RDI treatments were imposed between mid-June and mid-October in a flood-irrigated orchard. Continuing this same experiment for 4 years, Johnson et al. (1992) demonstrated continued productivity, reduced vegetative growth, substantial savings of water and no indication of decreased tree health or vigor. The main drawback to the RDI treatment was an increase in fruit doubles (Fig. 2A). A single postharvest irrigation in early August effectively reduced the level of this disorder but still provided substantial water savings. Subsequent work with a May-harvested peach cultivar using microsprinkler irrigation documented another fruit quality disorder, termed "deep suture" (Fig. 2B), associated with late-season water stress (Handley, 1991; Handley and Johnson, 2000). Alleviation of water stress by irrigating between early August and early September reduced the incidence of both doubles and deep sutures to the level of the fully irrigated control (Table 1). Microscopic examination of developing fruit buds showed that carpel differentiation was occurring in late August and early September. Therefore, the practice of reducing or eliminating irrigation after harvest of early maturing peach cultivars appears to be a feasible means of saving water without reducing production, as long as stress is alleviated during the period of carpel differentiation.

Similar treatments were imposed on an early-maturing plum $(P$. salicina L.) cultivar irrigated with foggers (Johnson et al., 1994). Even under extensive water stress, no double fruit or deep sutures were induced. However, completely cutting off irrigation led to partial defoliation within a few weeks and subsequent loss of yield. In trees that were irrigated daily, but at half the rate of the fully irrigated control, no reduction in yield or fruit quality occurred over a 3-year period.

Other researchers have reported negative effects of postharvest water stress on apricot ( $P$. armeniaca L.) fruit (Brown, 1953; Uriu, 1964). This could be due to the severity of stress but may also reflect differences in species. Additional research is needed to determine how well different species under different conditions can tolerate postharvest stress.

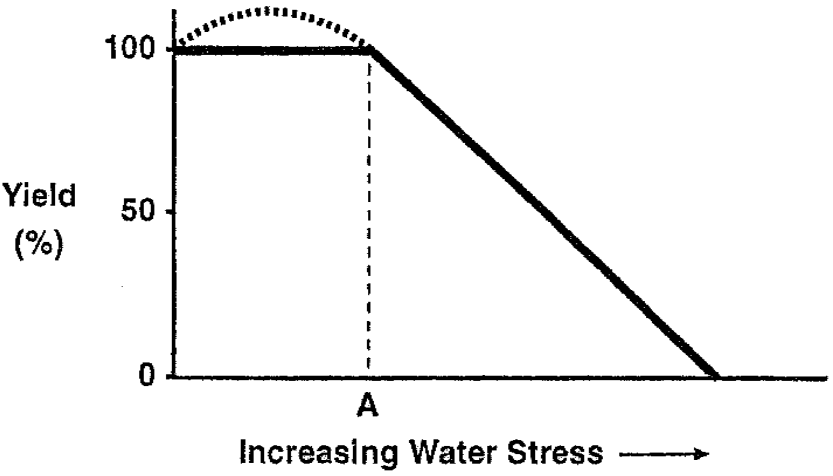

Fig. 1. The theoretical response of fruit growth and yield to water stress. As moderate stress is imposed, there is no reduction (and sometimes even an increase) in fruit growth or yield until point A is reached. 

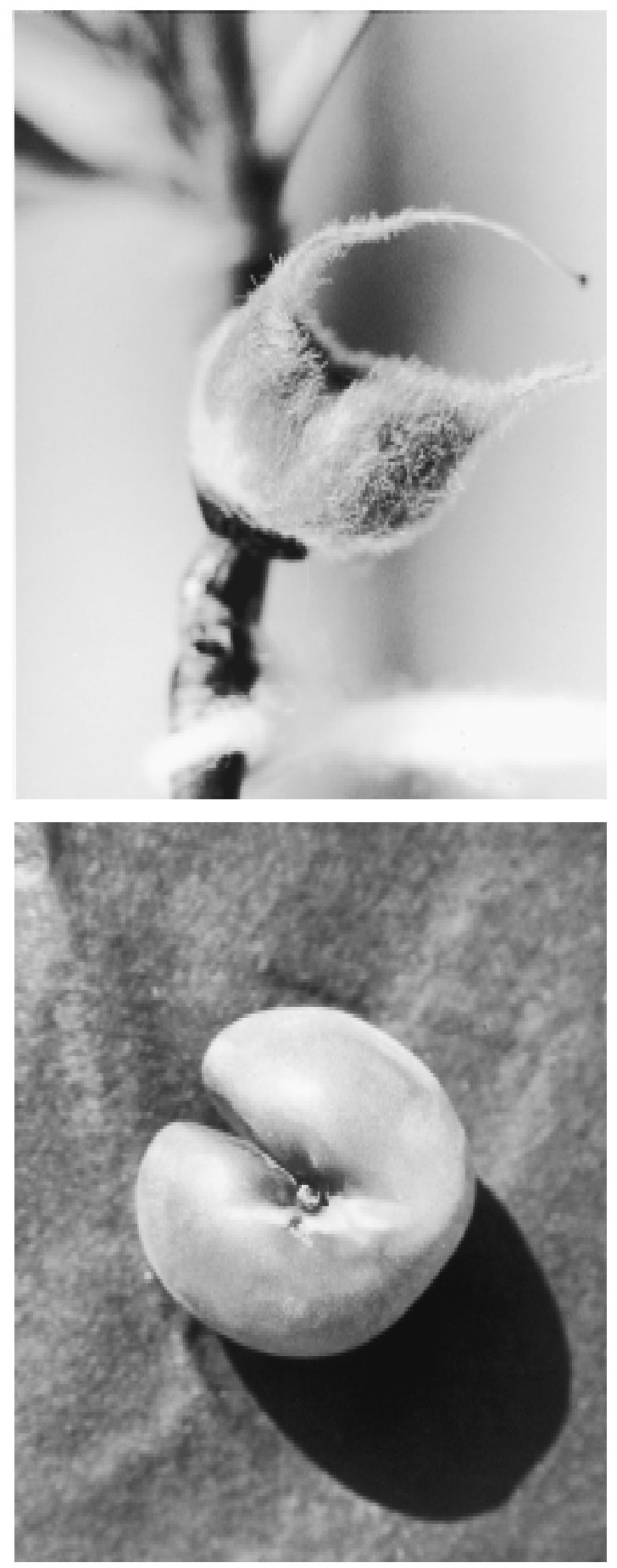

Fig. 2. Fruit disorders of peach that can be substantially increased by latesummer water stress: (top) fruit double and (bottom) deep suture.

Table 1. The effect of postharvest water stress in 1990 on incidence of double fruit and deep suture malformation of 'Spring Lady' peach at thinning and harvest time in $1991 .^{2}$

\begin{tabular}{llcc}
\hline \hline & \multicolumn{3}{c}{ Treatment } \\
\cline { 2 - 4 } Malformation & Control $^{\mathrm{y}}$ & Stressed $^{\mathrm{x}}$ & Rewatered $^{\mathrm{w}}$ \\
\hline Percentage of: & & & \\
$\quad$ Doubles at thinning & $7.5 \mathrm{~b}^{\mathrm{v}}$ & $44.8 \mathrm{a}$ & $2.9 \mathrm{~b}$ \\
Doubles at harvest & $0.3 \mathrm{~b}$ & $4.2 \mathrm{a}$ & $0.3 \mathrm{~b}$ \\
Deep sutures at harvest & $4.4 \mathrm{~b}$ & $10.1 \mathrm{a}$ & $4.1 \mathrm{~b}$ \\
\hline
\end{tabular}

${ }^{2}$ Source: Handley and Johnson (2000).

${ }^{y}$ Trees received $100 \% \mathrm{ET}_{\mathrm{c}}$ (calculated from reference crop water use $\left(\mathrm{ET}_{\mathrm{o}}\right)$ and crop coefficients $(\mathrm{Kc})$ for deciduous fruit trees) during the growing season.

${ }^{x}$ Trees received $100 \% \mathrm{ET}_{\text {c }}$ through harvest in May, then 25\% ET through October.

wSame as stressed except for $132 \% \mathrm{ET}_{\mathrm{c}}$ during August.

${ }^{v}$ Mean separation within rows by DMRT $(P \leq 0.05)$.

\section{WATER STRESS DURING FRUIT GROWTH}

It has been hypothesized that water stress imposed during the lag phase of stone fruit growth will have a much greater effect on reducing vegetative growth than reproductive growth. If full irrigation (or greater) is restored during the final, rapid phase of fruit growth, reduced competition from vegetative growth should allow final fruit size to be equal to or greater than that of fully irrigated controls. Studies on peach trees in Australia during the early 1980s supported this hypothesis (Chalmers et al., 1981, 1984; Mitchell and Chalmers, 1982). Increases in fruit size and yields of up to $30 \%$ were reported. The same researchers subsequently carried out similar experiments on pear (Pyrus communis L.), although pears do not exhibit a lag phase (Chalmers et al., 1985), and reported similar results (Mitchell et al., 1984, 1986, 1989). Again, RDI produced yields equal to or $20 \%$ greater than that of the controls. The authors proposed that fruit osmoregulation accounted for the stimulation of fruit growth upon resuming irrigation (Chalmers et al., 1986).

Other researchers in several countries have tried to replicate this technique, but have generally been less successful. Some have reported negative effects of RDI on fruit size in apple (Malus domestica Borkh.) (Ebel et al., 1993) and peach (Girona, 1989); others have reported no significant reduction in fruit size of apple (Ebel et al., 1995; Irving and Drost, 1987), Asian pear (Behboudian and Lawes, 1994; Caspari et al., 1994), and peach (Li et al., 1989; Strabbioli, 1992), but none have shown the substantial increase in fruit size reported from Australia. After 5 years of RDI treatments on peach in California, we observed an increase in fruit weight $(8 \%)$ in only the fifth year of the experiment (R.S. Johnson, unpublished data). Even though substantial increases in yield and/or fruit size were not observed in these experiments, the effects can still be considered beneficial, given the substantial savings of water with no significant loss in productivity.

Why does RDI appear to work in Australia but not as well elsewhere in the world? First, stress may need to be applied before the lag phase of fruit growth. Li et al. (1989) imposed stress treatments during different periods of peach fruit growth. They found no change in fruit size by stressing during the lag phase of growth, but a significant increase by imposing stress during the first phase of rapid fruit growth. Furthermore, the Australian workers often withheld water during early fruit growth, which may have contributed to the success of their experiments. Perhaps the emphasis should be on imposing stress early enough in the season so vegetative growth can be substantially reduced.

Second, the degree and duration of stress may also be important factors. The experiments in Australia were conducted on a shallow soil. Theoretically, trees in this condition could be put into and brought out of stress more quickly than those in a deeper soil. In a deeper soil there may not be sufficient time to develop the stress necessary to substantially inhibit vegetative growth early in the season. Because water stress during the last rapid phase of fruit growth invariably reduces fruit size (Behboudian and Lawes, 1994; Caspari et al., 1994), the stress must be alleviated quickly. Again, this can be a problem on deeper soils, especially if penetration of water into the soil is slow (Girona et al., 1993). Further research is needed to fine-tune the timing, duration and degree of stress needed to obtain consistent results from RDI treatments.

\section{FUTURE RESEARCH}

Many studies have shown that moderate water stress can provide beneficial effects in temperate fruit trees. The key to obtaining consistent and predictable results will be a better understanding of how water stress affects physiological processes in the plant. For example, Chalmers et al. (1986) hypothesized that RDI causes osmotic adjustment in the fruit, which can then increase growth rates. What are the conditions that maximize osmotic adjustment in the fruit? The timing of stress is obviously important (Behboudian and Lawes, 1994; Mills et al., 1996) but the duration, degree and rate of stress development could also be determining factors. Furthermore, there may be significant interactions with other factors, such as crop load (Berman and DeJong, 1996). 
Chalmers et al. (1984) suggested that root growth is the variable controlling vegetative vigor and fruitfulness under RDI treatments. What is the underlying physiological mechanism for this? Does a tree maintain a constant root-to-shoot ratio (Richards and Rowe, 1977), and how is this ratio affected by stress, planting density, irrigation type, pruning, soil type, etc.?

The better we understand how stress affects various physiological processes within the tree, the more likely we will be able to exploit its beneficial effects under various environmental, soil and cultural conditions. Much has still to be learned about how moderate water stress affects vegetative growth and productivity in fruit trees. However, over the last two decades research has clearly shown that stress can be imposed in ways to reduce vegetative growth, yet maintain productivity, while saving significant amounts of water.

\section{Literature Cited}

Behboudian, M.H. and G.S. Lawes. 1994. Fruit quality in 'Nijisseiki' Asian pear under deficit irrigation: physical attributes, sugar and mineral content, and development of flesh spot decay. N.Z. J. Crop Hort. Sci. 22:393-400.

Behboudian, M.H. and T.M. Mills. 1997. Deficit irrigation in deciduous orchards. Hort. Rev. 21:105-131.

Berman, M.E. and T.M. DeJong. 1996. Water stress and crop load effects on fruit fresh and dry weights in peach (Prunus persica). Tree Physiol. 16:859-864.

Bradford, K.J. and T.C. Hsiao. 1982. Physiological responses to moderate water stress, p. 263-324. In: O.L. Lange, P.S. Nobel, C.B. Osmond, and H. Zieler (eds.). Physiological plant ecology. Springer-Verlag, New York.

Brown, D.S. 1953. The effects of irrigation on flower bud development and fruiting in the apricot. Proc. Amer. Soc. Hort. Sci. 61:119-124.

Caspari, H.W., M.H. Behboudian, and D.J. Chalmers. 1994. Water use, growth, and fruit yield of 'Hosui' Asian pears under deficit irrigation. J. Amer. Soc. Hort. Sci. 119:383-388.

Chalmers, D.J., G. Burge, P.H. Jerie, and P.D. Mitchell. 1986. The mechanism of regulation of 'Bartlett' pear fruit and vegetative growth by irrigation withholding and regulated deficit irrigation. J. Amer. Soc. Hort. Sci. 111:904-907.

Chalmers, D.J., P.D. Mitchell, and P.H. Jerie. 1984. The physiology of growth of peach and pear trees using reduced irrigation. Acta Hort. 146:143-149.

Chalmers, D.J., P.D. Mitchell, and P.H. Jerie. 1985. The relation between irrigation, growth and productivity of peach trees. Acta Hort. 173:283-288.

Chalmers, D.J., P.D. Mitchell, and L. van Heek. 1981. Control of peach tree growth and productivity by regulated water supply, tree density, and summer pruning. J. Amer. Soc. Hort. Sci. 106:307-312.

Ebel, R. C., E.L. Proebsting, and R.G. Evans. 1995. Deficit irrigation to control vegetative growth in apple and monitoring fruit growth to schedule irrigation. HortScience 30:1229-1232.

Ebel, R.C., E.L. Proebsting, and M.E. Patterson. 1993. Regulated deficit irrigation may alter apple maturity, quality, and storage life. HortScience 28:141-143.

Girona, J. 1989. Physiological, growth and production responses of late maturing peach (Prunus persica $\mathrm{L}$. Batsch) to controlled deficit irrigation. MS Thesis, Dept. of Pomology, Univ. of California, Davis.

Girona, J., M. Mata, D.A. Goldhamer, R.S. Johnson, and T.M. DeJong. 1993.
Patterns of soil and tree water status and leaf functioning during regulated deficit irrigation scheduling in peach. J. Amer. Soc. Hort. Sci. 118:580586.

Handley, D.F. 1991. The formation of double fruit in peaches in response to postharvest deficit irrigation. MS Thesis, Dept. of Plant Sci., California State Univ., Fresno.

Handley, D.F. and R.S. Johnson. 2000. Late summer irrigation of waterstressed peach trees reduces fruit doubles and deep sutures. HortScience $35: 771$.

Hanks, R.J. 1983. Yield and water-use relationships: An overview. p. 393-411. In: H. Taylor, W.R. Jordan, and T.R. Sinclair (eds). Limitations to efficient water use in crop production. Amer. Soc. Agron., Crop Soc. Amer., Soil Sci. Soc. Amer.

Higgs, K.H. and H.G. Jones. 1991. Water relations and cropping of apple cultivars on a dwarfing rootstock in response to imposed drought. J. Hort. Sci. 66:367-379.

Irving, D.E. and J.H. Drost. 1987. Effects of water deficit on vegetative growth, fruit growth and fruit quality in Cox's Orange Pippin apple. J. Hort. Sci. 62:427-432.

Johnson, R.S., D.F. Handley, and K.R. Day. 1994. Postharvest water stress of an early maturing plum. J. Hort. Sci. 69:1035-1041.

Johnson, R.S., D.F. Handley, and T.M. DeJong. 1992. Long-term response of early maturing peach trees to postharvest water deficits. J. Amer. Soc. Hort. Sci. 117:881-886.

Larson, K.D., T.M. DeJong, and R.S. Johnson. 1988. Physiological and growth responses of mature peach trees to postharvest water stress. J. Amer. Soc. Hort. Sci. 113:296-300.

Lenz, F. 1967. Relationships between the vegetative and reproductive growth of Washington navel orange cuttings (Citrus sinensis L. Osbeck). J. Hort. Sci. 42:31-39.

Li, S.H., J.G. Huguet, P.G. Schoch, and P. Orlando. 1989. Response of peach tree growth and cropping to soil water deficit at various phenological stages of fruit development. J. Hort. Sci. 64:541-552.

Lilleland, O. 1933. Growth study of the peach fruit. Proc. Amer. Soc. Hort. Sci. 29:8-12.

Mills, T.M., M.H. Behboudian, and B.E. Clothier. 1996. Water relations, growth, and the composition of 'Braeburn' apple fruit under deficit irrigation. J. Amer. Soc. Hort. Sci. 121:286-291.

Mitchell, P.D. and D.J. Chalmers. 1982. The effect of reduced water supply on peach tree growth and yields. J. Amer. Soc. Hort. Sci. 107:853-856.

Mitchell, P.D., D.J. Chalmers, P.H. Jerie, and G. Burge. 1986. The use of initial withholding of irrigation and tree spacing to enhance the effect of regulated deficit irrigation on pear trees. J. Amer. Soc. Hort. Sci. 111:858-861.

Mitchell, P.D., P.H. Jerie, and D.J. Chalmers. 1984. The effects of regulated water deficits on pear tree growth, flowering, fruit growth, and yield. J. Amer. Soc. Hort. Sci. 109:604-606.

Mitchell, P.D., B. van den Ende, P.H. Jerie, and D.J. Chalmers. 1989. Responses of 'Bartlett' pear to withholding irrigation, regulated deficit irrigation, and tree spacing. J. Amer. Soc. Hort. Sci. 114:15-19.

Richards, D. and R.N. Rowe. 1977. Root-shoot interactions in peach: The function of the root. Ann. Bot 41:1211-1216.

Sharp, R.E. and W.J. Davies. 1975. Solute regulation and growth by roots and shoots of water-stressed maize plants. Planta 147:43-49.

Strabbioli, G. 1992. The influence of regulated deficit irrigation (RDI) on the growth and productivity of peach trees. Acta Hort. 315:211-217.

Uriu, K. 1964. Effect of post-harvest soil moisture depletion on subsequent yield of apricots. Proc. Amer. Soc. Hort. Sci. 84:93-97. 